\title{
Controlled hyperkalemic reperfusion with magnesium rescues ischemic juvenile hearts by reducing calcium loading
}

\author{
Hajime Imura, MD, ${ }^{\mathrm{a}}$ Hua Lin, MSc, ${ }^{\mathrm{b}}$ Elinor J. Griffiths, $\mathrm{PhD},{ }^{\mathrm{b}, \mathrm{c}}$ and M.-Saadeh Suleiman, PhD, DSc ${ }^{\mathrm{b}}$
}

Objectives: Our objectives were (1) to determine whether elevated $\mathrm{Mg}^{2+}$ in controlled hyperkalemic reperfusate without intervention during ischemia protects the juvenile heart against reperfusion injury; and (2) to identify the mechanism(s) underlying any protective effect of $\mathrm{Mg}^{2+}$.

\begin{abstract}
Methods: Langendorff-perfused hearts from juvenile (11- to 14-day-old) guinea pigs were subjected to mild (30-minute) or severe (45-minute) normothermic global ischemia and 35-minute reperfusion. Hearts were subjected to controlled hyperkalemic reperfusion without or with various concentrations of $\mathrm{Mg}^{2+}(5,10$, 16, $23 \mathrm{mM})$. The mechanisms underlying the effect of $\mathrm{Mg}^{2+}$ on intracellular $\mathrm{Ca}^{2+}\left(\left[\mathrm{Ca}^{2+}\right] \mathrm{i}\right)$ were also studied in isolated cardiomyocytes exposed to metabolic inhibition followed by washout using hyperkalemic solutions (reperfusion).
\end{abstract}

Results: Sixteen $\mathrm{mM} \mathrm{Mg}^{2+}$ conferred maximal cardioprotection as assessed by improved functional recovery and reduced cardiac injury; this was associated with a significant recovery of cardiac energetics and metabolism following both mild and severe ischemia. The $\mathrm{Mg}^{2+}$-induced protection was additive to that of hyperkalemia following mild ischemia and conferred protection following severe ischemia when hyperkalemia alone had no significant effect. Elevated $\mathrm{Mg}^{2+}$ in the hyperkalemic reperfusate of cardiomyocytes acutely prevented $\left[\mathrm{Ca}^{2+}\right]$ i loading following mild metabolic inhibition and augmented the fall in $\left[\mathrm{Ca}^{2+}\right]$ i following severe metabolic inhibition.

Conclusions: This work demonstrates for the first time in juvenile hearts that elevated $\mathrm{Mg}^{2+}$ during controlled hyperkalemic reperfusion rescues the heart following ischemia, and that this is likely to be facilitated by reducing $\left[\mathrm{Ca}^{2+}\right] \mathrm{i}$ which, in turn, would aid metabolic recovery. (J Thorac Cardiovasc Surg 2011;141:1529-37)

Existing clinical interventions employed to protect the heart against reperfusion injury during surgery aim to improve cardiac function by reducing the metabolic and ionic derangements that occur during ischemia, including the fall of energy-rich phosphates, the accumulation of lactic acid, and the rise in the intracellular concentrations of $\mathrm{Na}^{+}$ $\left(\left[\mathrm{Na}^{+}\right]_{\mathrm{i}}\right), \mathrm{Mg}^{2+}\left(\left[\mathrm{Mg}^{2+}\right]_{\mathrm{i}}\right)$, and $\mathrm{Ca}^{2+}\left(\left[\mathrm{Ca}^{2+}\right]_{\mathrm{i}}\right){ }^{1}$ A common protective strategy is hyperkalemic cardioplegic arrest, which depolarizes the plasma membrane and arrests the heart. Supplementing hyperkalemic cardioplegia with $\mathrm{Mg}^{2+}\left(\left[\mathrm{Mg}^{2+}\right]_{\mathrm{o}}\right)$ confers additional protection to the adult heart during coronary artery bypass graft surgery, ${ }^{2}$ reducing $\mathrm{Ca}^{2+}$ loading, ${ }^{3}$ and improving cytosolic free energy. ${ }^{4}$

It is becoming increasingly evident that controlling the conditions of reperfusion and the composition of the initial

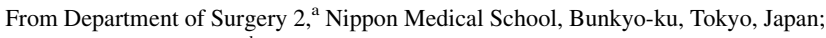
Bristol Heart Institute, ${ }^{\mathrm{b}}$ Bristol, United Kingdom; and Department of Biochemistry, ${ }^{\mathrm{c}}$ University of Bristol, Bristol, United Kingdom.

Disclosures: Authors have nothing to disclose with regard to commercial support. Received for publication June 23, 2010; revisions received Aug 17, 2010; accepted for publication Sept 2, 2010; available ahead of print Dec 20, 2010.

Address for reprints: Elinor J. Griffiths, PhD, Department of Biochemistry, School of Medical Sciences, University Walk, Bristol BS8 1TD, UK (E-mail: Elinor. Griffiths@bristol.ac.uk).

$0022-5223 / \$ 36.00$

Copyright (c) 2011 by The American Association for Thoracic Surgery doi:10.1016/j.jtcvs.2010.09.048
}

reperfusate without any intervention during ischemia can also be used to rescue the myocardium. ${ }^{5}$ Such interventions include elevated $\left[\mathrm{Mg}^{2+}\right]_{\mathrm{o}}$ given during reperfusion of isolated rat and human tissue. ${ }^{6,7}$ However, these studies using controlled reperfusion have focused on adult hearts. Because there are differences in the vulnerability to cardiac insults between adult and juvenile hearts and in the efficacy of interventions to protect the heart, ${ }^{8,9}$ strategies that work in the adult heart may not be effective in the immature heart.

The objectives of this study were (1) to investigate the cardioprotective action of $\mathrm{Mg}^{2+}$ during controlled hyperkalemic reperfusion of juvenile hearts exposed to a mild or severe ischemic insult; and (2) to identify potential mechanism(s) underlying any protective effect of elevated $\left[\mathrm{Mg}^{2+}\right]_{\mathrm{o}}$ using a model of simulated ischemia/reperfusioninjury isolated cardiomyocytes from juvenile and adult hearts. Changes in $\left[\mathrm{Ca}^{2+}\right]_{\mathrm{i}}$ and cardiac energy status are implicated in determining the cardioprotective efficacy of controlled reperfusion in the adult heart. ${ }^{5}$

\section{MATERIALS AND METHODS \\ Animals}

Juvenile guinea pigs ( 11 to 14 days old) were killed by cervical dislocation, and the hearts were quickly removed, rinsed in ice cold Tyrode solution (composition in mM: $135 \mathrm{NaCl} ; 5.4 \mathrm{KCl} ; 2 \mathrm{CaCl}_{2} ; 1 \mathrm{MgCl}_{2} ; 5 \mathrm{Na}$-pyruvate, 


\section{Abbreviations and Acronyms \\ HR = heart rate \\ HPLC = high-performance liquid chromatography \\ LVDP $=$ left ventricular developed pressure \\ LVEDP $=$ left ventricular end diastolic pressure \\ $\mathrm{LDH}=$ lactate dehydrogenase}

$0.33 \mathrm{NaH}_{2} \mathrm{PO}_{4}, 10$ glucose; 10 HEPES-NaOH; at $\mathrm{pH} 7.3$ ), and allocated either to experiments involving intact heart preparations or to experiments involving isolated ventricular myocytes. All animals were cared for in a stress-free and controlled environment and treated in accordance with the Home Office Guidance on the Operation of Animals (Scientific Procedures) Act, 1986 (HMSO, London); the experiments were approved by the university's ethical review board. The investigation conforms with the Guide for the Care and Use of Laboratory animals published by the US National Institutes of Health (NIH Publication No. 85-23, revised 1996).

\section{Isolated Perfused Heart Preparations}

Experimental protocols. Excised juvenile hearts were Langendorff-perfused with $100 \%$ oxygenated Tyrode solution at a constant flow of $13 \mathrm{~mL}$ minutes ${ }^{-1} \mathrm{~g}^{-1}$ wet weight; resulting in an average perfusion pressure of $60 \mathrm{~mm} \mathrm{Hg}$. Hearts were perfused to allow stabilization for 30 minutes before induction of global ischemia ( 30 or 45 minutes) induced by switching off the pump and immersing the heart in Tyrode solution at $37^{\circ} \mathrm{C}$. In the control group, reperfusion was restarted with normal Tyrode for 35 minutes. In the experimental groups, there was an initial 2- or 5 -minutes reperfusion with hyperkalemic buffer $(20 \mathrm{mM} \mathrm{K})$ and $\left[\mathrm{Mg}^{2+}\right]$ of $5,10,16$, or $23 \mathrm{mM}$ (see Figure 1).

Measurements of functional recovery. Functional recovery on reperfusion was assessed by measuring left ventricular developed pressure (LVDP), left ventricular end diastolic pressure (LVEDP), and heart rate (HR). Ventricular pressure was measured by inserting a latex balloon into the left ventricle through the mitral valve. The balloon was tied to the end of a polyethylene tube connected to pressure transducer, filled with water, and kept isovolumic throughout. Six hearts with LVDP $>50 \mathrm{~mm} \mathrm{Hg}$ were used for each intervention, giving a total of 72 animals.

Determinization of reperfusion injury. Lactate dehydrogenase $(\mathrm{LDH})$ leakage into coronary effluent during reperfusion was measured to determine the extent of cell damage. Coronary effluent was collected for a 30 -second period just before ischemia and at intervals for 30 minutes after ischemia. The activity of LDH was determined using a diagnostic kit from Sigma (Gillingham, UK), and the values are expressed as IU/mL.

Measurement of myocardial metabolites. Hearts from a separate group of juvenile guinea pigs were used to collect myocardial tissue for the measurement of metabolites. Three myocardial biopsies were collected from perfused hearts at the beginning and end of ischemia and at the end of controlled hyperkalemic reperfusion without or with $16 \mathrm{mM}$ $\mathrm{Mg}^{2+}$. This concentration of $\mathrm{Mg}^{2+}$ was selected because it induced maximal protection (see Results). Biopsies were immediately frozen and stored in liquid nitrogen for analysis of metabolites.

Frozen tissue samples were crushed to powder in liquid nitrogen, transferred to ice-cold $4.8 \%$ perchloric acid, mixed, and centrifuged at $1500 \times g$ for 10 minutes at $4^{\circ} \mathrm{C}$. The supernatant was then neutralized using $0.44 \mathrm{M}$ $\mathrm{K}_{2} \mathrm{CO}_{3}$ and was centrifuged again at $1500 \times g$ for 10 minutes at $4^{\circ} \mathrm{C}$, after which the supernatant was collected for high-performance liquid chromatography (HPLC) analysis. The pellet was taken for the measurement of protein concentration using a Sigma Protein Assay Kit. The concentrations

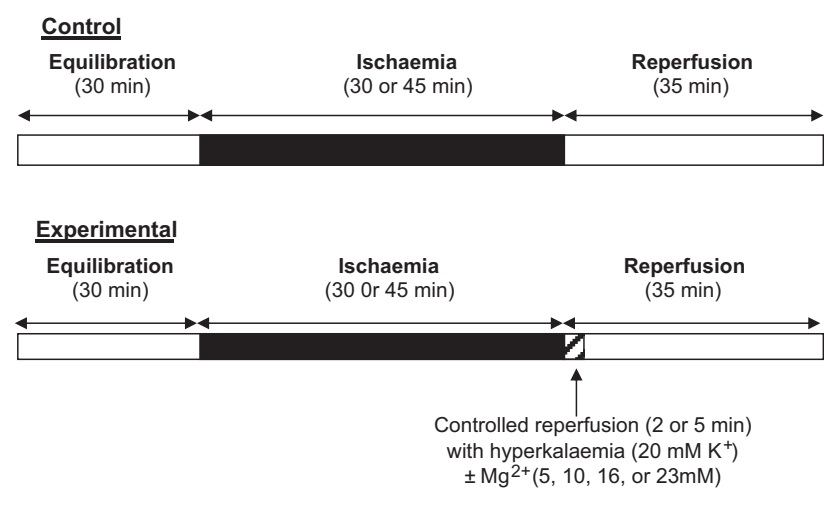

FIGURE 1. Schematic presentation of the experimental protocols followed in this study. In control experiments, Langendorff-perfused juvenile (11-14 days) guinea-pig hearts were exposed to 30 or 45 minutes of normothermic global ischemia followed by reperfusion for 35 minutes with normal buffer. In the experimental protocols (intervention) hearts were exposed to 30 or 45 minutes of normothermic global ischemia followed by 2 or 5 minutes of controlled hyperkalemia reperfusion with or without $\mathrm{Mg}^{2+}(5,10,16$, or $23 \mathrm{mM})$.

of adenine nucleotides (ATP, ADP, and AMP) and other byproducts of ATP catabolism (the nucleosides inosine and adenosine, and the purines hypoxanthine and xanthine) were measured using a Beckman HPLC machine as described previously. ${ }^{10}$ Myocardial lactate in the extract was measured using a commercially available kit from Sigma. The concentration of metabolites was expressed as $\mathrm{nmol} / \mathrm{mg}$ protein.

The energy status of myocardial tissue before ischemia and after reperfusion was determined by calculating the adenylate energy charge. This is an index of the metabolic status and reflects the ability of the cell to make energy-rich phosphates from precursors and was calculated as follows:

$$
\text { Energy Charge }=(0.5 A D P+A T P) /(A M P+A D P+A T P)
$$

The ratios ATP/ADP and ATP/AMP were calculated and used to reflect the phosphorylation potential of the cardiomyocyte.

\section{Isolated Perfused Ventricular Cardiomyocyte Preparations}

Isolation of ventricular cardiomyocytes and measurement of fluorescence. Single ventricular cardiomyocytes were isolated as previously described ${ }^{11}$ and stored in isolation buffer (composition in mM: $20 \mathrm{Na}$ HEPES, $130 \mathrm{NaCl}, 4.5 \mathrm{KCl}, 5 \mathrm{MgCl}_{2}, 1 \mathrm{NaH}_{2} \mathrm{PO}_{4}, 21$ glucose, 5 pyruvate, and the $\mathrm{pH}$ adjusted to 7.25 with $\mathrm{NaOH}$ ) plus $2 \mathrm{mM}$ $\mathrm{CaCl}_{2}$ until use.

For measurement of intracellular $\left[\mathrm{Ca}^{2+}\right]\left(\left[\mathrm{Ca}^{2+}\right]_{\mathrm{i}}\right), 3 \mathrm{~mL}$ of cell suspension were incubated with $10 \mu \mathrm{M}$ indo-1 acetoxymethyl ester (indo-1/AM)(Molecular Probes, Invitrogen, Paisley, UK) [or 10 minutes at $35^{\circ} \mathrm{C}$; this promotes cytosolic loading of the indicator with little mitochondrial compartmentation. ${ }^{12}$ Cells were centrifuged for 1 minute at $1500 \times g$ and resuspended in $5 \mathrm{~mL}$ of isolation buffer containing $2 \mathrm{mM} \mathrm{CaCl}_{2}$. A small portion of the indo-1-loaded cells was placed in an experimental chamber mounted on the stage of an inverted microscope (Nikon Diaphot 300). The normal Tyrode superfusate contained (mM): $137 \mathrm{NaCl}, 5 \mathrm{KCL}, 1.2 \mathrm{MgSO}_{4}$, $1.2 \mathrm{NaH}_{2} \mathrm{PO}_{4}, 16 \mathrm{D}$-glucose, $2 \mathrm{CaCl}_{2}, 20 \mathrm{HEPES}$, adjusted to $\mathrm{pH} 7.4$ with $\mathrm{NaOH}$ at $37^{\circ} \mathrm{C}$. The myocyte to be studied was illuminated by a red light and its image visualized using a TV camera and monitor. Indo-1 was excited at $350 \pm 5 \mathrm{~nm}$ and emission was detected at $410 \pm 5 \mathrm{~nm}$ and 490 $\pm 5 \mathrm{~nm}$; results were presented as the $410 / 490$ ratio. Fluorescent light was detected and collected on-line by a Newcastle Photometric Systems 

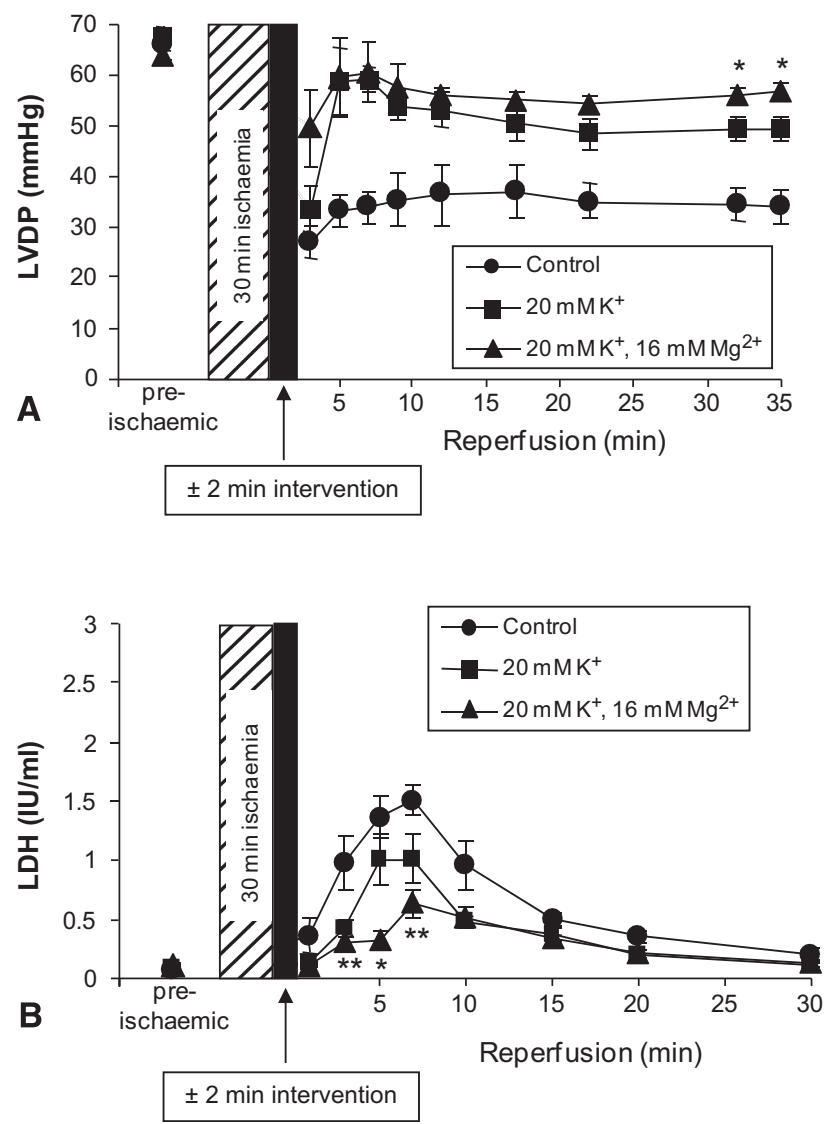

FIGURE 2. Effect of $16 \mathrm{mM} \mathrm{Mg}^{2+}$ during hyperkalemic controlled reperfusion on functional recovery (LVDP) and cardiac injury (LDH release) in isolated perfused juvenile hearts exposed to a mild ischemic insult. Measurements were made prior to ischemia and at different time points during reperfusion for LVDP (A) and LDH (B). Data are presented as mean \pm SEM ( $\mathrm{n}=6 /$ group). LVDP in the control group was significantly $(P<.05)$ lower during reperfusion at all time points taken after 5 minutes. $* P<.05$ vs other groups at same time point. $* * P<.05$ vs control at same time point.

Photon Counting System (Newcastle, UK). Light was collected at a rate of up to 1 data point per $30 \mathrm{~ms}$ from a single myocyte.

\section{Metabolic Inhibition and Experimental Protocols}

Two experimental models of metabolic inhibition and washout (reperfusion), both severe and mild, were used to investigate the effects of $16 \mathrm{mM}$ $\left[\mathrm{Mg}^{2+}\right]_{\mathrm{o}}$ on $\left[\mathrm{Ca}^{2+}\right]_{\mathrm{i}}$. In each model juvenile myocytes were superfused with normal Tyrode solution to obtain steady-state cardiomyocyte activity, indicated by a response to field stimulation with no arrhythmias, before induction of metabolic inhibition by superfusion with buffer devoid of glucose containing $5 \mathrm{mM} \mathrm{NaCN}$. In control myocytes reperfusion was induced by return to normal Tyrode, and experimental groups were reperfused for 2 or 5 minutes with hyperkalemic buffer without or with $16 \mathrm{mM} \mathrm{Mg}{ }^{2+}$. Clearly this is not technically reperfusion because myocytes are continuously superfused, but we find it useful when describing the various protocols and for comparison with the whole heart experiments.

Model 1: Mild metabolic inhibition. This model aimed to induce a $\mathrm{Ca}^{2+}$ load only upon reperfusion but not during metabolic inhibition. Myocytes were superfused for 45 minutes with buffer devoid of glucose and containing $5 \mathrm{mM} \mathrm{NaCN}$ and stimulated at $0.4 \mathrm{~Hz}$ before reperfusion with or without hyperkalemia $(20 \mathrm{mM} \mathrm{K})^{\dagger} \pm 16 \mathrm{mM}\left[\mathrm{Mg}^{2+}\right]_{\mathrm{o}}$ for 30 minutes. All cells recovered $\mathrm{Ca}^{2+}$ transients and contractile response to stimulation.

Model 2: Severe metabolic inhibition. Myocytes were stimulated at $2 \mathrm{~Hz}$ and exposed to metabolic inhibition until they underwent rigor contracture. Cells were allowed to stay in rigor for 10 minutes, which induced a marked rise in $\left[\mathrm{Ca}^{2+}\right]_{\mathrm{i}}$ during the insult. Previously we have found that $\left[\mathrm{Ca}^{2+}\right]_{\mathrm{i}}$ increases only following rigor development in this model and that recovery correlates with the extent of the $\left[\mathrm{Ca}^{2+}\right]_{\mathrm{i}}$ increase. ${ }^{11}$

\section{Statistical Analysis}

Data are expressed as mean \pm SEM. Statistical analysis was performed using a StatView package. The statistical significance of the data was determined by using Student $t$ test and where appropriate analysis of variance (ANOVA, factorial or repeated measures) combined with Fisher protected least significant difference post hoc test. Differences were accepted as significant when $P<0.05$. Total release of LDH was calculated as area under the curve using the Trapezium rule available in Excel.

\section{RESULTS \\ Effect of $\mathrm{Mg}^{2+}$ During Hyperkalemic-Controlled Reperfusion of Isolated Perfused Hearts}

Mild ischemia. Controlled reperfusion for 2 minutes with hyperkalemia resulted in cardiac arrest during the controlled reperfusion period but subsequently in improved recovery and reduced injury (Figure 2). The presence of $16 \mathrm{mM}\left[\mathrm{Mg}^{2+}\right]_{\mathrm{o}}$ in the hyperkalemia conferred a significant additional improvement in recovery (Figure 2), but the addition of other concentrations of $\mathrm{Mg}^{2+}$ did not show a further improvement (Figure 3, A). Cardiac cell injury, as assessed by time-dependent LDH release, was also reduced by hyperkalemia plus $\mathrm{Mg}^{2+}$ and to a greater extent than by hyperkalemia alone (Figure 3, $B$ ), although the total LDH release did not reach statistical significance (Figure 3,B). The full hemodynamic data for control and for hyperkalemia with or without $16 \mathrm{mM} \mathrm{Mg}^{2+}$ are given in Table 1 .

Severe ischemia. In the experiments, hyperkalemia alone improved recovery to more than $70 \%$, which may explain the relatively small beneficial effect of $\mathrm{Mg}^{2+}$. Therefore hearts were exposed to global normothermic ischemia for 45 minutes which, as expected, resulted in greater functional impairment and cell injury (LDH release) upon reperfusion than did 30 minutes of ischemia (Figure 4). However, 2 minutes of hyperkalemic-controlled reperfusion with or without $\mathrm{Mg}^{2+}$ did not show a significant improvement in hearts exposed to 45 minutes of ischemia (data not shown). Therefore a series of experiments were carried out to determine whether there was an optimal duration of controlled reperfusion with hyperkalemia plus $\mathrm{Mg}^{2+}$ that was effective. A duration of 5 minutes of hyperkalemic-controlled reperfusion with $16 \mathrm{mM} \mathrm{Mg}^{2+}$ was cardioprotective and reduced reperfusion injury in hearts exposed to a severe ischemia insult of 45 minutes' duration (Figure 4). Hyperkalemia alone or with $5 \mathrm{mM} \mathrm{Mg}^{2+}$ did not protect, even though it arrested the heart, whereas other $\mathrm{Mg}^{2+}$ concentrations (10 and 23 $\mathrm{mM}$ ) conferred significant protection (Figure 3,C and $D$ ). The full hemodynamic data for control and hyperkalemia with or without $16 \mathrm{mM} \mathrm{Mg}^{2+}$ are given in Table 2 . 

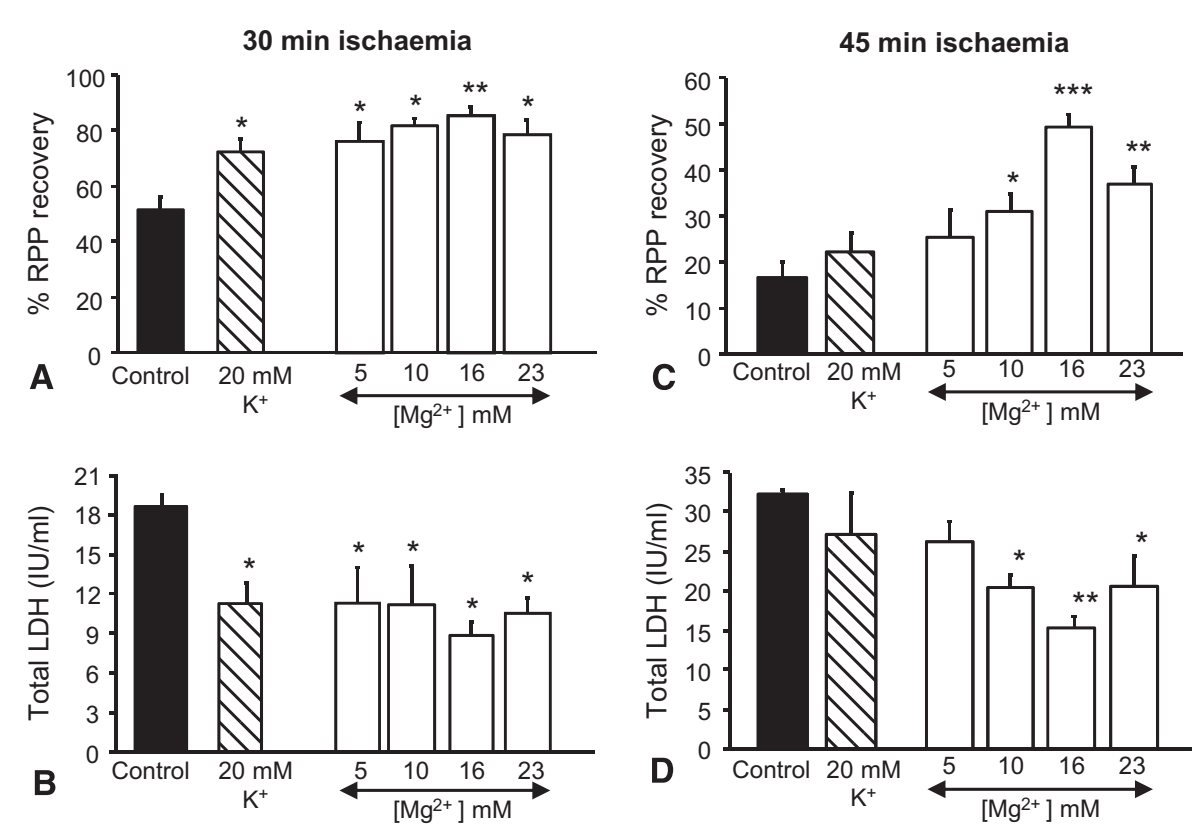

FIGURE 3. Effect of different concentrations of extracellular $\mathrm{Mg}^{2+}$ during hyperkalemic controlled reperfusion in isolated perfused juvenile hearts exposed to a mild ( $\mathrm{A}$ and $\mathrm{B}$ ) or severe ( $\mathrm{C}$ and $\mathrm{D}$ ) ischemic insult. Functional recovery was calculated as the final measurement of RPP (rate pressure product) as percentage of basal level (A and C). Cardiac injury (total LDH release) is shown in B and D. Data are presented as mean $\pm \mathrm{SEM}(\mathrm{n}=6 / \mathrm{group}) . * P<.05$ vs control. $* * P<.05$ vs control and $20 \mathrm{~K}^{+}$.

\section{Changes in Myocardial Metabolites During Controlled Hyperkalemic Reperfusion With or Without $\mathbf{M g}^{2+}$}

Experiments described thus far have shown that the cardioprotective efficacy of $16 \mathrm{mM} \mathrm{Mg}^{2+}$ in the hyperkalemic reperfusate depends on both the duration of the ischemia and the duration of the controlled reperfusion with $\mathrm{Mg}^{2+}$; protection was most evident after a severe ischemic insult. Hyperkalemia alone was effective only following mild ischemia. This is intriguing because hyperkalemia induces cardiac arrest (and presumably metabolic preservation)

TABLE 1. Hemodynamic parameters I*

\begin{tabular}{|c|c|c|c|}
\hline & \multirow{2}{*}{$\frac{\text { Control }}{\text { Normal buffer }}$} & \multicolumn{2}{|c|}{ Experimental } \\
\hline & & $20 \mathbf{K}^{+}$ & $20 \mathrm{~K}^{+}, 16 \mathrm{Mg}^{2+}$ \\
\hline \multicolumn{4}{|l|}{ Basal } \\
\hline LVDP (mm Hg) & $66 \pm 3$ & $68 \pm 2$ & $64 \pm 2$ \\
\hline HR & $232 \pm 7$ & $229 \pm 7$ & $237 \pm 9$ \\
\hline LVEDP (mm Hg) & $2.3 \pm 0.8$ & $2.6 \pm 0.6$ & $3.2 \pm 0.6$ \\
\hline \multicolumn{4}{|l|}{ End of reperfusion } \\
\hline $\begin{array}{r}\text { LVDP }(\mathrm{mm} \mathrm{Hg}) \\
(\% \text { recovery })\end{array}$ & $34 \pm 3 \dagger(52 \%)$ & $49 \pm 2(74 \%)$ & $57 \pm 2(89 \%)$ \\
\hline HR (\% recovery) & $232 \pm 10(97 \%)$ & $227 \pm 10(100 \%)$ & $224 \pm 4(95 \%)$ \\
\hline LVEDP $(\mathrm{mm} \mathrm{Hg})$ & $15.7 \pm 2.0 \dagger, \ddagger$ & $8.3 \pm 1.0 \dagger$ & $6.7 \pm 0.7 \dagger$ \\
\hline \multicolumn{4}{|c|}{$\begin{array}{l}H R \text {, heart rate; } L V D P \text {, left ventricular developed pressure; } L V E D P \text {, left ventricular end } \\
\text { diastolic pressure. *Hemodynamic parameters were measured before and after } 30 \\
\text { minutes of ischemia with or without } 2 \text { minutes of controlled reperfusion. End-of- } \\
\text { reperfusion measurements were made after } 35 \text { minutes of reperfusion. Mean } \pm \mathrm{SE} \\
\text { (n=6/group). } \dagger P<.05 \text { vs corresponding basal level. } \ddagger P<.05 \text { vs end of reperfusion } \\
\text { for other groups. }\end{array}$} \\
\hline
\end{tabular}

under both conditions. Therefore, the effect of controlled reperfusion on myocardial metabolites following mild or severe ischemia was studied (Figure 5 and Tables 3 and 4). As expected, following 30 minutes of (mild) ischemia, there was a fall in ATP and a rise in myocardial lactate in myocardial biopsies collected at the end of the ischemic periods (Figure 5, $A$ and $B$ ). The presence of $16 \mathrm{mM} \mathrm{Mg}^{2+}$ did not appear to alter levels of these metabolites after 2 minutes of controlled reperfusion (Figure 5, $A$ and $C$ ) despite the hearts' showing better recovery (Figure 2). However, the ATP/ADP and ATP/AMP ratios were better maintained in the $\mathrm{Mg}^{2+}$ group (Table 3).

By contrast, following 45 minutes of ischemia and 5 minutes of controlled reperfusion, ATP levels were significantly higher in the group containing $\mathrm{Mg}^{2+}$, whereas lactate levels were significantly lower than with hyperkalemia alone (Figure 5, $C$ and $D$ ). Again, the ATP/ADP, ATP/AMP ratios and energy charges were also better preserved in the $\mathrm{Mg}^{2+}$ treated group (Table 4). Changes in other metabolites are shown in Tables 3 and 4.

\section{The Effect of $\mathrm{Mg}^{2+}$ on Intracellular $\mathrm{Ca}^{2+}$ in Isolated Perfused Cardiomyocytes During Hyperkalemic-Controlled Reperfusion Following Metabolic Inhibition}

To determine whether the protective effect of $\mathrm{Mg}^{2+}$ resulted from reduced $\mathrm{Ca}^{2+}$ loading, isolated ventricular myocytes were used to investigate whether there was a direct 

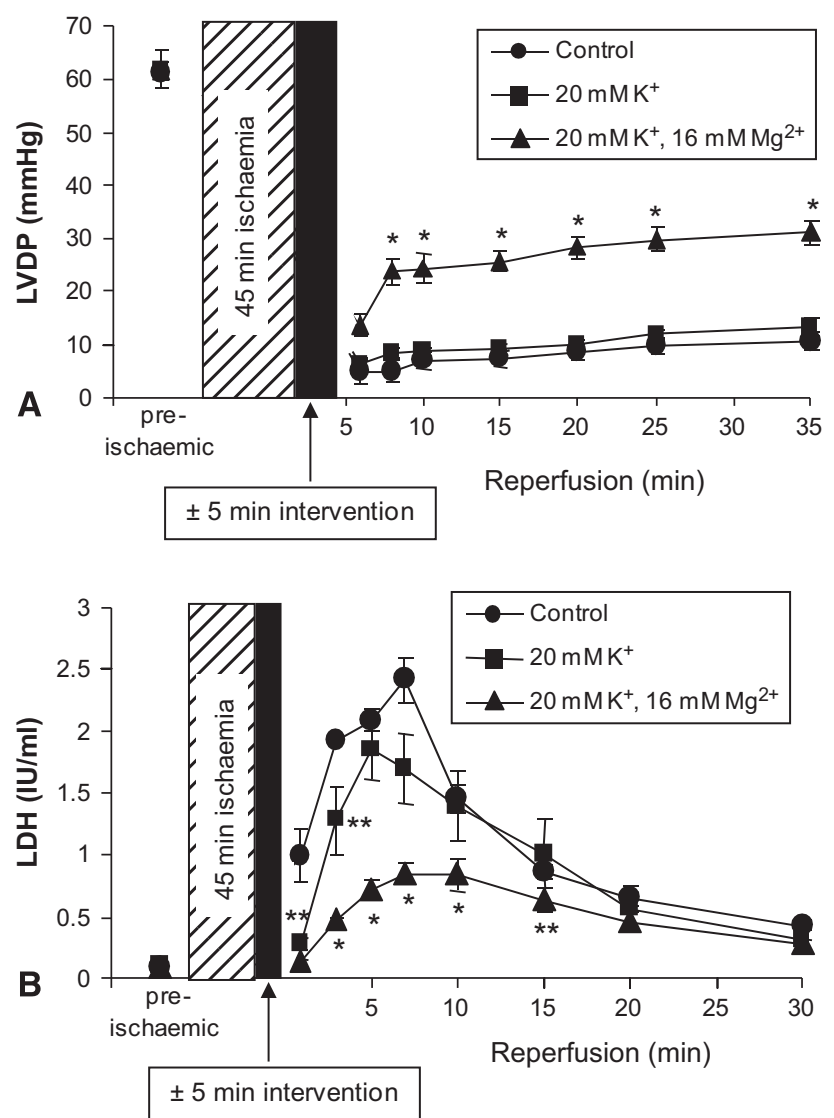

FIGURE 4. Effect of $16 \mathrm{mM} \mathrm{Mg}^{2+}$ during hyperkalemic controlled reperfusion on functional recovery (LVDP) and cardiac injury (LDH release) in isolated perfused juvenile hearts exposed to a severe (45-minute) ischemic insult. Measurements were made prior to ischemia (basal) and at different time points during reperfusion for LVDP (A) and LDH (B). Data are presented as mean \pm SEM ( $\mathrm{n}=6$ /group). LVDP in the $20 \mathrm{~K}, 16 \mathrm{Mg}$ group was significantly $(P<.05)$ lower during reperfusion at all time points. $* P<.05$ vs other groups at same time point. $* * P<.05$ vs control at same time point.

relationship between $\left[\mathrm{Mg}^{2+}\right]_{\mathrm{o}}$ and $\left.\left[\mathrm{Ca}^{2+}\right]_{\mathrm{i}}\right]$ during mild or severe models of metabolic inhibition followed by washout of inhibitors (reperfusion; see Methods).

In the mild model, cells stimulated at $0.4 \mathrm{~Hz}$ were exposed to metabolic inhibition ( $5 \mathrm{mM} \mathrm{NaCN}$, no glucose) for 45 minutes followed by return to normal Tyrode (control) or subjected to controlled hyperkalemic reperfusion without or with $16 \mathrm{mM} \mathrm{Mg}^{2+}$. In control cells $\left[\mathrm{Ca}^{2+}\right]_{\mathrm{i}}$ increased only on reperfusion, and this increase was sustained for the reperfusion period (Figure 6, A). Controlled reperfusion with hyperkalemia alone did not significantly alter this trend. However, the addition of $16 \mathrm{mM} \mathrm{Mg}{ }^{2+}$ greatly limited the increase in $\left[\mathrm{Ca}^{2+}\right]_{\mathrm{i}}$, on reperfusion, which returned to the prehypoxic level (Figure 6, A). Throughout this time there was little change in myocyte morphology or contractility, with cells continuing to respond in time with the stimulus.
TABLE 2. Hemodynamic parameters II*

\begin{tabular}{|c|c|c|c|}
\hline & \multirow{2}{*}{$\frac{\text { Control }}{\text { Normal buffer }}$} & \multicolumn{2}{|c|}{ Experimental } \\
\hline & & $20 \mathrm{~K}^{+}$ & $20 \mathrm{~K}^{+}, 16 \mathrm{Mg}^{2+}$ \\
\hline \multicolumn{4}{|l|}{ Basal } \\
\hline LVDP (mm Hg) & $61 \pm 1$ & $61 \pm 1$ & $62 \pm 2$ \\
\hline HR & $227 \pm 4$ & $229 \pm 6$ & $33 \pm 6$ \\
\hline LVEDP (mm Hg) & $3.9 \pm 0.8$ & $5.1 \pm 0.5$ & $4.6 \pm 0.7$ \\
\hline \multicolumn{4}{|l|}{ End of reperfusion } \\
\hline $\begin{array}{l}\text { LVDP }(\mathrm{mm} \mathrm{Hg}) \\
(\% \text { recovery })\end{array}$ & $\begin{array}{l}10.6 \pm 1.7 \dagger \\
(17 \%)\end{array}$ & $\begin{array}{l}15.4 \pm 3.6 \dagger \\
(26 \%)\end{array}$ & $\begin{array}{l}31.2 \pm 2.2 \dagger, \ddagger \\
(50 \%)\end{array}$ \\
\hline HR (\% recovery) & $219 \pm 8(97 \%)$ & $229 \pm 7(100 \%)$ & $228 \pm 5(98 \%)$ \\
\hline LVEDP $(\mathrm{mm} \mathrm{Hg})$ & $30.1 \pm 6.2 \dagger$ & $27.6 \pm 3.2 \dagger$ & $15.4 \pm 2.0 \dagger, \ddagger$ \\
\hline \multicolumn{4}{|c|}{$\begin{array}{l}H R \text {, heart rate; } L V D P \text {, left ventricular developed pressure; } L V E D P \text {, left ventricular end } \\
\text { diastolic pressure. } * \text { Hemodynamic parameters measured before and after } 45 \text { minutes } \\
\text { of ischemia with or without } 5 \text { minutes of controlled reperfusion. End of reperfusion } \\
\text { measurements were made after } 35 \text { minutes of reperfusion. Mean } \pm \mathrm{SE}(\mathrm{n}=6 / \text { group). } \\
\text { Changes in myocardial metabolites in ventricular biopsies collected before (basal), } \\
\text { end of } 30 \text { minutes ischemia, and } 2 \text { minutes after controlled reperfusion with } 20 \mathrm{~K}^{+} \\
\text {or } 20 \mathrm{~K}^{+}, 16 \mathrm{Mg}^{2+} \text {. Mean } \pm \mathrm{SE} \text { ( } \mathrm{n}=6 / \text { group). } \dagger P<.05 \text { vs corresponding basal level. } \\
\ddagger P<.05 \mathrm{vs} \text { end of reperfusion for other groups. }\end{array}$} \\
\hline
\end{tabular}

In the severe model, myocytes stimulated at $2 \mathrm{~Hz}$ were exposed to metabolic inhibition ( $5 \mathrm{mM} \mathrm{NaCN}$, no glucose) until they entered the rigor state. Cells were allowed to remain in rigor for 10 minutes, during which time there was a marked and significant rise in $\left[\mathrm{Ca}^{2+}\right]_{\mathrm{i}}$ (Figure 6, B). Reperfusion with normal buffer and basal stimulation $(0.2 \mathrm{~Hz})$ resulted in a further small rise in resting $\left[\mathrm{Ca}^{2+}\right]_{\mathrm{i}}$ before $\left[\mathrm{Ca}^{2+}\right]_{\mathrm{i}}$ declined gradually, although remaining significantly higher than basal levels (Figure 6, $B$ ). Controlled hyperkalemic reperfusion without or with $16 \mathrm{mM} \mathrm{Mg}^{2+}$ accelerated the fall of $\left[\mathrm{Ca}^{2+}\right]_{\mathrm{I}}$; in the $\mathrm{Mg}^{2+}$-treated group, the final $\left[\mathrm{Ca}^{2+}\right]_{\mathrm{i}}$ was not significantly different from basal levels (Figure 6, $B$ ). At the end of reperfusion, only $17 \%$ of cells contracted in time with the stimulus, and $50 \%$ showed $\mathrm{Ca}^{2+}$ transients. For the hyperkalemia group these values were $33 \%$ and $67 \%$, respectively, whereas for the added $16 \mathrm{mM} \mathrm{Mg}^{2+}$ group the recovery was $67 \%$ and $100 \%$ for contraction and $\mathrm{Ca}^{2+}$ transients, respectively.

\section{DISCUSSION}

This work demonstrates for the first time that in juvenile hearts controlled hyperkalemic reperfusion with elevated $\left[\mathrm{Mg}^{2+}\right]_{\mathrm{o}}$ rescues the heart from reperfusion injury. The efficacy of $\mathrm{Mg}^{2+}$ depends on its concentration as well as on the durations of both ischemia and controlled reperfusion. It is important to note that after severe ischemia, elevated $\left[\mathrm{Mg}^{2+}\right]_{\mathrm{o}}$ was effective in preventing reperfusion damage when hyperkalemia alone was ineffective; this was associated with improved cardiac metabolism and energy status. Experiments using an isolated myocyte model of metabolic inhibition demonstrated that elevated $\left[\mathrm{Mg}^{2+}\right]_{\mathrm{o}}$ during controlled hyperkalemic reperfusion acutely inhibited $\mathrm{Ca}^{2+}$ loading. This reduced $\mathrm{Ca}^{2+}$ loading is therefore likely to be the cause of improved metabolic recovery at the end of controlled hyperkalemic reperfusion with elevated $\left[\mathrm{Mg}^{2+}\right]_{\mathrm{o}}$. 

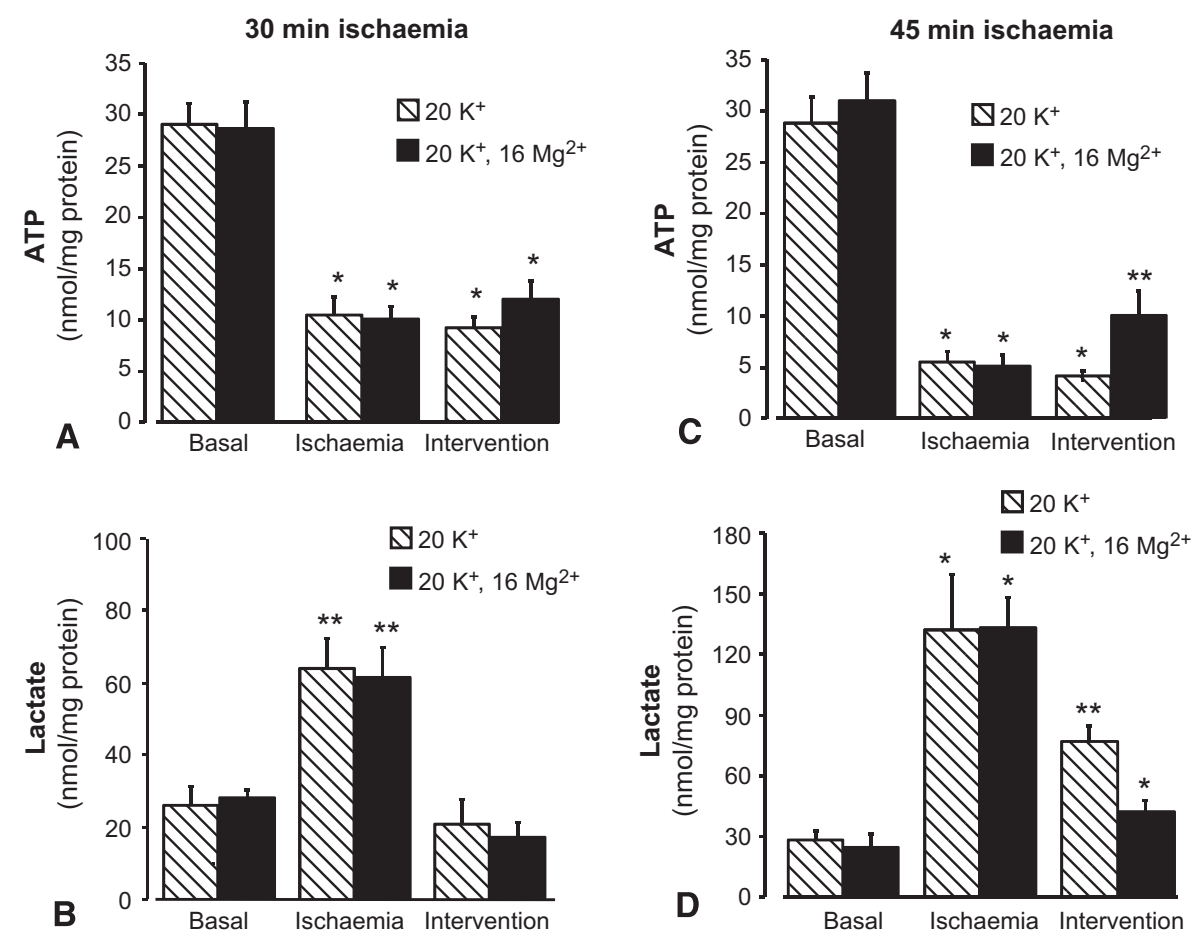

FIGURE 5. Effect of $16 \mathrm{mM} \mathrm{Mg}^{2+}$ during hyperkalemic controlled reperfusion on myocardial concentration of ATP (A and B) and lactate(C and D) in biopsies collected from isolated perfused juvenile hearts at the beginning (basal) and end of a mild (A and C) or severe (B and D) ischemic insult followed by 2 or 5 minutes of controlled reperfusion (intervention). Data are presented as mean \pm SEM. $* P<.05$ vs basal level. $* * P<.05$ vs corresponding basal and intervention levels. $\dagger P<.05$ vs the $-\mathrm{Mg}^{2+}$ intervention group.

How these changes compare with those in adult or aged hearts is not currently known. Studies of adult hearts or comparing adult and aged hearts investigated the effect of elevated $\left[\mathrm{Mg}^{2+}\right]_{0}$; hyperkalemia was introduced during index ischemia, ${ }^{3,13-15}$ although not during reperfusion (as in this study), and this also correlated with a reduction in $\mathrm{Ca}^{2+}$ loading.

\section{$\mathrm{Mg}^{2+}$, Hyperkalemia, and Protection of the Juvenile Heart}

During postnatal development, cardiomyocytes undergo morphologic, metabolic, energetic, and ionic changes, ${ }^{16,17}$ so it is not surprising that there are controversies regarding age-related differences in vulnerability to cardiac insults and in the efficacy of various cardioprotective strategies. ${ }^{18,19}$ With the advent of recent strategies to protect the adult heart by controlling the conditions of reperfusion without intervention during ischemia, ${ }^{20,21}$ it has become essential to determine whether the juvenile heart can also be protected using this approach. Our choice to use hyperkalemic solutions to investigate the efficacy of elevated $\left[\mathrm{Mg}^{2+}\right]_{\mathrm{o}}$ is important because they form the basis of cardioplegic solutions used during the ischemic period

TABLE 3. Changes in metabolites I*

\begin{tabular}{|c|c|c|c|c|c|c|}
\hline \multirow[b]{2}{*}{ Metabolites and ratios } & \multicolumn{3}{|c|}{$\mathbf{2 0 \mathbf { K } ^ { + }}$} & \multicolumn{3}{|c|}{$20 \mathrm{~K}^{+}, 16 \mathrm{Mg}^{2+}$} \\
\hline & Basal & Ischemia & Controlled reperfusion & Basal & Ischemia & Controlled reperfusion \\
\hline ATP & $28.9 \pm 2.1$ & $10.3 \pm 1.8 \dagger$ & $9.3 \pm 1.2 \dagger$ & $28.7 \pm 2.4$ & $10.0 \pm 1.2 \dagger$ & $11.9 \pm 1.9 \dagger$ \\
\hline $\mathrm{ADP}$ & $26.0 \pm 3.7$ & $11.3 \pm 2.5 \dagger$ & $10.7 \pm 0.9 \dagger$ & $24.5 \pm 2.7$ & $12.6 \pm 1.72 \dagger$ & $10.3 \pm 1.1 \dagger$ \\
\hline AMP & $13.4 \pm 3.4$ & $14.9 \pm 2.9$ & $8.1 \pm 0.9 \dagger$ & $10.5 \pm 1.7$ & $12.8 \pm 1.8$ & $8.0 \pm 1.6 \dagger$ \\
\hline IMP & $4.7 \pm 1.3$ & $7.3 \pm 2.0$ & $8.2 \pm 1.4$ & $4.6 \pm 1.1$ & $8.3 \pm 0.9 \dagger$ & $8.4 \pm 1.6 \dagger$ \\
\hline Inosine & $3.25 \pm 0.66$ & $9.95 \pm 2.26 \dagger$ & $5.9 \pm 0.73 \ddagger$ & $2.26 \pm 0.39$ & $9.76 \pm 1.52 \dagger$ & $6.78 \pm 1.0 \dagger$ \\
\hline Adenosine & $0.26 \pm 0.04$ & $0.26 \pm 0.05$ & $0.26 \pm 0.02$ & $0.27 \pm 0.05$ & $0.26 \pm 0.04$ & $0.25 \pm 0.04$ \\
\hline Hypoxanthine & $0.90 \pm 0.22$ & $2.95 \pm 0.62 \dagger$ & $1.70 \pm 0.20 \dagger$ & $0.93 \pm 0.11$ & $2.89 \pm 0.40 \dagger$ & $1.83 \pm 0.30 \dagger$ \\
\hline ATP/ADP & $1.19 \pm 0.14$ & $0.96 \pm 0.12 \dagger$ & $0.86 \pm 0.08 \dagger$ & $1.2 \pm 0.09$ & $0.83 \pm 0.08 \dagger$ & $1.19 \pm 0.19$ \\
\hline ATP/AMP & $2.85 \pm 0.69$ & $0.82 \pm 0.23 \dagger$ & $1.28 \pm 0.29 \dagger$ & $3.04 \pm 0.44$ & $0.85 \pm 0.13 \dagger$ & $1.76 \pm 0.33 \dagger$ \\
\hline Adenylate energy charge & $1.10 \pm 0.16$ & $0.77 \pm 0.07 \dagger$ & $0.97 \pm 0.16$ & $0.95 \pm 0.08$ & $0.72 \pm 0.02 \dagger$ & $0.84 \pm 0.09$ \\
\hline
\end{tabular}

$H R$, heart rate; $L V D P$, left ventricular developed pressure; $L V E D P$, left ventricular end diastolic pressure. ${ }^{*}$ Changes in myocardial metabolites in ventricular biopsies collected before(basal), at end of 30 minutes of ischemia, and 2 minutes after controlled reperfusion with $20 \mathrm{~K}^{+}$or $20 \mathrm{~K}^{+}, 16 \mathrm{Mg}^{2+}$. Mean $\pm \mathrm{SE}$ ( $\mathrm{n}=6 /$ group). $\nmid P<.05 \mathrm{vs}$ corresponding basal level $\ddagger P<.05$ vs corresponding basal and ischemic levels. 
TABLE 4. Changes in metabolites II*

\begin{tabular}{|c|c|c|c|c|c|c|}
\hline \multirow[b]{2}{*}{ Metabolites and ratios } & \multicolumn{3}{|c|}{$\mathbf{2 0} \mathbf{K}^{+}$} & \multicolumn{3}{|c|}{$20 \mathrm{~K}^{+}, 16 \mathrm{Mg}^{2+}$} \\
\hline & Basal & Ischemia & Controlled reperfusion & Basal & Ischemia & Controlled reperfusion \\
\hline ATP & $28.8 \pm 2.5$ & $5.5 \pm 1.0 \dagger$ & $4.1 \pm 0.3 \dagger$ & $30.9 \pm 2.8$ & $5.1 \pm 0.7 \dagger$ & $10.1 \pm 2.1 \ddagger$ \\
\hline ADP & $24.4 \pm 2.1$ & $8.3 \pm 1.0 \dagger$ & $7.9 \pm 0.5 \dagger$ & $27.1 \pm 1.6$ & $7.7 \pm 1.0 \dagger$ & $11.3 \pm 1.0 \dagger$ \\
\hline AMP & $12.1 \pm 0.4$ & $11.9 \pm 1.0$ & $9.0 \pm 0.8 \dagger$ & $11.1 \pm 0.5$ & $11.7 \pm 0.9$ & $7.9 \pm 2.0$ \\
\hline IMP & $4.4 \pm 0.4$ & $11.9 \pm 0.6 \dagger$ & $11.2 \pm 0.8 \dagger$ & $4.7 \pm 0.4$ & $11.4 \pm 1.6 \dagger$ & $9.1 \pm 1.7 \dagger$ \\
\hline Inosine & $2.2 \pm 0.3$ & $11.3 \pm 0.9 \dagger$ & $8.1 \pm 0.7 \dagger$ & $2.2 \pm 0.5$ & $11.4 \pm 1.0 \dagger$ & $6.9 \pm 1.6 \dagger$ \\
\hline Adenosine & $0.29 \pm 0.03$ & $0.41 \pm 0.08$ & $0.41 \pm 0.07$ & $0.29 \pm 0.05$ & $0.42 \pm 0.05$ & $0.47 \pm 0.11$ \\
\hline Hypoxanthine & $0.88 \pm 0.09$ & $3.66 \pm 0.25 \dagger$ & $2.43 \pm 0.29 \ddagger$ & $0.93 \pm 0.10$ & $3.67 \pm 0.31 \dagger$ & $1.90 \pm 0.36 \ddagger$ \\
\hline ATP/ADP & $1.20 \pm 0.12$ & $0.64 \pm 0.06 \dagger$ & $0.53 \pm 0.03 \ddagger$ & $1.14 \pm 0.07$ & $0.67 \pm 0.06 \dagger$ & $0.85 \pm 0.10 \dagger$ \\
\hline ATP/AMP & $2.38 \pm 0.19$ & $0.45 \pm 0.06 \dagger$ & $0.48 \pm 0.07 \dagger$ & $2.83 \pm 0.32$ & $0.46 \pm 0.08 \dagger$ & $1.54 \pm 0.33 \ddagger$ \\
\hline Adenylate energy charge & $1.35 \pm 0.13$ & $0.99 \pm 0.11 \dagger$ & $1.14 \pm 0.17 \dagger$ & $1.46 \pm 0.20$ & $0.96 \pm 0.08 \dagger$ & $1.38 \pm 0.23 \S$ \\
\hline
\end{tabular}

$H R$, heart rate; $L V D P$, left ventricular developed pressure; $L V E D P$, left ventricular end diastolic pressure. *Changes in myocardial metabolites in ventricular biopsies collected before (basal), end of 45 minutes of ischemia, and 5 minutes after controlled reperfusion with $20 \mathrm{~K}^{+}$or $20 \mathrm{~K}^{+}, 16 \mathrm{Mg}^{2+}$. Mean $\pm \mathrm{SE}$ (n $=6 / \mathrm{group}$ ). $\dagger P<.05 \mathrm{vs}$ corresponding basal level. $\ddagger P<.05$ vs corresponding basal and ischemia levels. $\S P<.05$ vs corresponding ischemia levels.

to arrest the adult and juvenile myocardium during surgery. ${ }^{2,22}$

In this study, following mild ischemia, the protective effect of elevated $\left[\mathrm{Mg}^{2+}\right]_{0}$ over that of hyperkalemia alone was evident only at $16 \mathrm{mM} \mathrm{Mg}{ }^{2+}$; other concentrations showed no difference. By contrast, following a severe ischemic insult, elevated $\left[\mathrm{Mg}^{2+}\right]_{\mathrm{o}}$ at 10,16 , and $23 \mathrm{mM}$ showed significant protection at a time when hyperkalemia alone was ineffective. The cardioplegic role of hyperkalemia is to arrest the heart in diastole, thus preserving energy-rich phosphates. But it has been suggested that the rationale for including $\mathrm{Mg}^{2+}$ in cardioplegic solutions is not its cardioplegic properties, ${ }^{4}$ and that the added benefit of elevated $\left[\mathrm{Mg}^{2+}\right]_{\mathrm{o}}$ is likely to be to the result of any or all of the following: (1) an added metabolic effect; (2) reducing $\mathrm{Ca}^{2+}$ overload; (3) replenishing $\left[\mathrm{Mg}^{2+}\right]_{i}$ stores.

\section{Is Protection of the Juvenile Heart by Elevated $\left[\mathrm{Mg}^{2+}\right]_{0}$ Related to Improved Energy Status, Improved $\mathrm{Ca}^{2+}$ Handling, or Both?}

Despite its cardioprotective effects following mild ischemia, hyperkalemia alone or with elevated $\left[\mathrm{Mg}^{2+}\right]_{\mathrm{o}}$ did not significantly alter ATP levels (Figure 3, A). However, postischemic ATP levels have been shown to correlate poorly with functional recovery ${ }^{23}$ - ATP levels may not be restored rapidly if there is depletion of the adenine nucleotide pool $^{1}$ - and better correlation is seen when comparing the recovery with an adenylate energy charge or ATP/ADP ratio (Table 3). $\mathrm{Mg}^{2+}$ also reduced myocyte damage, as indexed by a reduction in the release of $\mathrm{LDH}$ during reperfusion (Figure 2, B).

As expected, the metabolic derangements were more marked in hearts following a severe ischemic insult (Figure 5 and Table 4). At the end of controlled reperfusion, hyperkalemia alone added little change to the metabolite levels or the cardiac energetics compared to end ischemic levels (Table 4). By contrast, the addition of $\mathrm{Mg}^{2+}$ to hyper- kalemia significantly improved metabolic recovery, including ATP, lactate, ATP/AMP, and adenylate energy charge (Figure 5 and Table 4). These data clearly indicate that one factor responsible for the cardioprotective effect of elevated $\left[\mathrm{Mg}^{2+}\right]_{\mathrm{o}}$ in controlled hyperkalemia is an improvement in metabolism and energetic state. It is worth emphasizing that the heart is arrested in both conditions (hyperkalemia alone or hyperkalemia with elevated $\mathrm{Mg}^{2+}$ ) and therefore the metabolic recovery is likely to be caused by improvement in basal metabolic activity not associated with contraction.

Our data on isolated perfused cardiomyocytes (Figure 6) support the view that the cardioprotection with $\mathrm{Mg}^{2+}$ is to the result of reduced $\mathrm{Ca}^{2+}$ loading; elevated $\mathrm{Mg}^{2+}$ prevented the increase in $\left[\mathrm{Ca}^{2+}\right]_{\mathrm{i}}$ during reperfusion during mild metabolic inhibition (Figure 6, A) and accelerated recovery of $\left[\mathrm{Ca}^{2+}\right]_{\mathrm{i}}$ to basal levels on reperfusion during severe metabolic inhibition (Figure 6, $B$ ). The efficacy of protection by elevated $\left[\mathrm{Mg}^{2+}\right]_{0}$ during controlled reperfusion with hyperkalemia seen in juvenile hearts may be related to the inhibition of L-type $\mathrm{Ca}^{2+}$ channels; work on adult guinea-pig myocytes has shown that $\mathrm{Mg}^{2+}$ inhibits the channel when present at concentrations of more than $10 \mathrm{mM},{ }^{24}$ and this would indirectly reduce metabolic demands triggered by a rise in intracellular $\mathrm{Ca}^{2+}$. The effects of elevated $\left[\mathrm{Mg}^{2+}\right]_{\mathrm{o}}$ may not be caused solely by the blocking of the $\mathrm{Ca}^{2+}$ channels; earlier work showed that elevated $\left[\mathrm{Mg}^{2+}\right]_{\mathrm{o}}$ provided superior protection than did $\mathrm{Ca}^{2+}$ channel blockers ${ }^{25}$; $\mathrm{Mg}^{2+}$ may also replenish intracellular energy stores because it has been shown that the fall in ATP during ischemia is followed very closely by a rise in $\left[\mathrm{Mg}^{2+}\right]_{\mathrm{i}} \cdot{ }^{1}$ Most of the $\left[\mathrm{Mg}^{2+}\right]_{\mathrm{i}}$ in the cardiomyocytes is found as Mg-ATP, so the loss of $\mathrm{Mg}^{2+}$ during ischemia may restrict the repletion of ATP upon reperfusion. ${ }^{4}$ This is critical because $\left[\mathrm{Mg}^{2+}\right]_{\mathrm{i}}$ does not respond rapidly to elevations in $\left[\mathrm{Mg}^{2+}\right]_{\mathrm{o}}{ }^{25}$ Therefore the slow replenishment of $\left[\mathrm{Mg}^{2+}\right]_{\mathrm{i}}$ may hinder recovery. Increasing the inward gradient of $\mathrm{Mg}^{2+}$ would increase its 

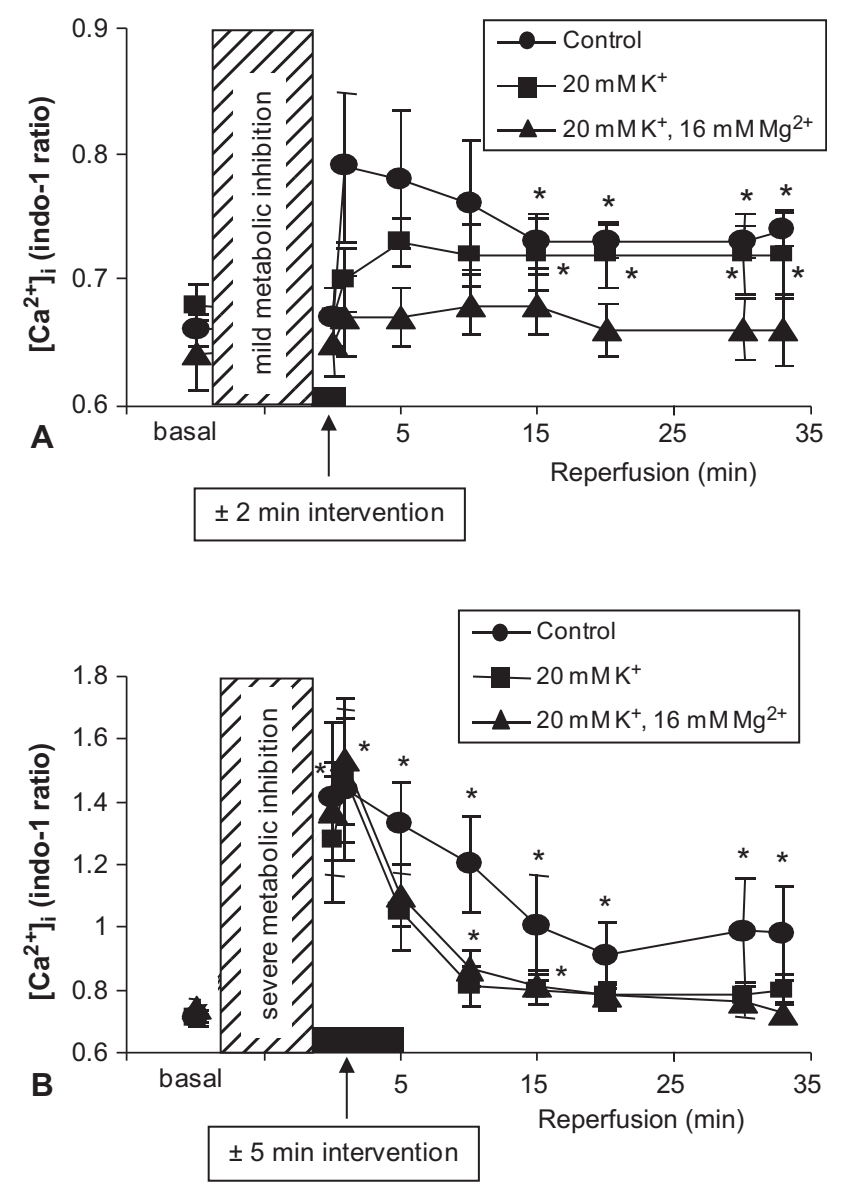

FIGURE 6. Effect of $16 \mathrm{mM} \mathrm{Mg}^{2+}$ during hyperkalemic controlled reperfusion on intracellular $\mathrm{Ca}^{2+}$ concentration $\left(\left[\mathrm{Ca}^{2+}\right]_{\mathrm{i}}\right.$ ) measured in isolated superfused cardiac myocytes exposed to mild or severe metabolic inhibition (see Methods). A, During severe metabolic inhibition myocytes enter rigor and $\left[\mathrm{Ca}^{2+}\right]_{i}$ increases markedly. On restoring normal perfusion conditions, $\left[\mathrm{Ca}^{2+}\right]_{\mathrm{i}}$ declines back gradually but not to basal levels. Initial controlled hyperkalemic reperfusion with or without $16 \mathrm{mM} \mathrm{Mg}^{2+}$ for 5 minutes accelerated the recovery in $\left[\mathrm{Ca}^{2+}\right]_{\mathrm{i}}$. B, During mild metabolic inhibition, cell morphology and $\left[\mathrm{Ca}^{2 \dagger}\right]_{\mathrm{i}}$ did not alter. However, restoring normal perfusion conditions induced a significant increase in $\left[\mathrm{Ca}^{2+}\right]_{\mathrm{i}}$. Controlled hyperkalemic reperfusion with $\mathrm{Mg}^{2+}$ for 2 minutes significantly prevented the rise in $\left[\mathrm{Ca}^{+2}\right]_{\mathrm{i}}$. However, $\left[\mathrm{Ca}^{2+}\right]_{\mathrm{i}}$ remained significantly higher than basal levels at most time points. Data are presented as mean $\pm \mathrm{SE}(\mathrm{n}=6$ /group). $* P<.05$ vs basal level.

influx and presumably aid in recovery. Exactly how $\mathrm{Mg}^{2+}$ accelerates the decline in $\mathrm{Ca}^{2+}$ upon the reperfusion seen in the myocyte model requires further investigation, but this study nevertheless has important implications for design of reperfusion-based protective strategies for the juvenile heart.

\section{Study Limitations}

Our study utilized both single cells and perfused hearts: Isolated cardiomyocytes enabled us to monitor cellular changes in $\mathrm{Ca}^{2+}$ without interference from the cardiovascu- lature. An isolated Langendorff-perfused heart is a starting model that is widely used to investigate the effects of cardiac insults and various interventions, including cardioplegic solutions. However, this heart model has limitations because it is not a working heart and is perfused with crystalloid buffer rather than blood. Therefore, the cardioprotective efficacy of $\mathrm{Mg}^{2+}$ in hyperkalemic solution needs to be further investigated in an in vivo model (eg, piglet) with or without cardiopulmonary bypass.

We acknowledge the support of the National Institute for Health Research Bristol Biomedical Research Unit.

\section{References}

1. Murphy E, Steenbergen C. Ion transport and energetics during cell death and protection. Physiology (Bethesda). 2008;23:115-23.

2. Caputo M, Bryan AJ, Calafiore AM, Suleiman MS, Angelini GD. Intermittent antegrade hyperkalemic warm blood cardioplegia supplemented with magnesium prevents myocardial substrate derangement in patients undergoing coronary artery bypass surgery. Eur J Cardiothorac Surg. 1998;14:596-601.

3. Tsukube T, McCully JD, Faulk EA, Federman M, LoCicero J 3rd, Krukenkamp IB, et al. Magnesium cardioplegia reduces cytosolic and nuclear calcium and DNA fragmentation in the senescent myocardium. Ann Thorac Surg. 1994;58:1005-11.

4. Shattock MJ, Hearse DJ, Fry CH. The ionic basis of the anti-ischemic and anti-arrhythmic properties of magnesium in the heart. J Am Coll Nutr. 1987;6: 27-33.

5. Beyersdorf $\mathrm{F}$. The use of controlled reperfusion strategies in cardiac surgery to minimize ischemia/reperfusion damage. Cardiovasc Res. 2009;83:262-8.

6. Lareau S, Boyle A, Deslauriers R, Keon WJ, Kroft T, Labow RS. Magnesium enhances function of postischemic human myocardial tissue. Cardiovasc Res. 1993;27:1009-14

7. Tosaki A, Szerdahelyi P, Engelman RM, Das DK. Effects of extracellular magnesium manipulation on reperfusion-induced arrhythmias and myocardial ion shifts in isolated ischemic reperfused rat hearts. J Pharmacol Exp Ther. 1993; 267:1045-53.

8. Modi P, Suleiman MS. Myocardial taurine, development and vulnerability to ischemia. Amino Acids. 2004;26:65-70.

9. O’Brien JD, Howlett SE, Burton HJ, O'Blenes SB, Litz DS, Friesen CL. Pediatric cardioplegia strategy results in enhanced calcium metabolism and lower serum troponin T. Ann Thorac Surg. 2009;87:1517-23.

10. Imura H, Caputo M, Parry A, Pawade A, Angelini GD, Suleiman MS. Age-dependent and hypoxia-related differences in myocardial protection during pediatric open heart surgery. Circulation. 2001;103:1551-6.

11. Williams H, Kerr PM, Suleiman M, Griffiths EJ. Differences in the calciumhandling response of isolated rat and guinea-pig cardiomyocytes to metabolic inhibition: implications for cell damage. Exp Physiol. 2000;85:505-10.

12. Griffiths EJ, Stern MD, Silverman HS. Measurement of mitochondrial calcium in single living cardiomyocytes by selective removal of cytosolic indo 1 . Am J Physiol. 1997;273(Pt 1):C37-44.

13. Ataka K, Chen D, McCully J, Levitsky S, Feinberg H. Magnesium cardioplegia prevents accumulation of cytosolic calcium in the ischemic myocardium. J Mol Cell Cardiol. 1993;25:1387-90.

14. Jimenez E, del Nido P, Feinberg H, Levitsky S. Redistribution of myocardial calcium during ischemia: relationship to onset of contracture. J Thorac Cardiovasc Surg. 1993;105:988-94.

15. Tsukube T, McCully JD, Federman M, Krukenkamp IB, Levitsky S. Developmental differences in cytosolic calcium accumulation associated with surgically induced global ischemia: optimization of cardioplegic protection and mechanism of action. J Thorac Cardiovasc Surg. 1996;112:175-84.

16. Marin-Garcia J, Ananthakrishnan R, Goldenthal MJ. Mitochondrial gene expression in rat heart and liver during growth and development. Biochem Cell Biol. 1997;75:137-42.

17. Artman M, Henry G, Coetzee WA. Cellular basis for age-related differences in cardiac excitation-contraction coupling. Prog Pediatr Cardiol. 2000;11:185-94.

18. Lopaschuk GD, Spafford MA. Differences in myocardial ischemic tolerance between 1- and 7-day-old rabbits. Can J Physiol Pharmacol. 1992;70:1315-23. 
19. Southworth R, Shattock MJ, Hearse DJ, Kelly FJ. Developmental differences in superoxide production in isolated guinea-pig hearts during reperfusion. $\mathrm{J} \mathrm{Mol}$ Cell Cardiol. 1998;30:1391-9.

20. Piper HM, Abdallah Y, Schafer C. The first minutes of reperfusion: a window of opportunity for cardioprotection. Cardiovasc Res. 2004;61:365-71.

21. Yellon DM, Hausenloy DJ. Myocardial reperfusion injury. N Engl J Med. 2007; 357:1121-35.

22. Engelman RM, Rousou JH, Lemeshow S, Dobbs WA. A clinical comparison of potassium and magnesium-potassium crystalloid cardioplegia: metabolic considerations. J Cardiovasc Surg (Torino. 1985;26:343-50.
23. Rosenkranz ER, Okamoto F, Buckberg GD, Vinten-Johansen J, Allen BS, Leaf J, et al. Biochemical studies: failure of tissue adenosine triphosphate levels to predict recovery of contractile function after controlled reperfusion. J Thorac Cardiovasc Surg. 1986;92:488-501.

24. Hall SK, Fry CH. Magnesium affects excitation, conduction, and contraction of isolated mammalian cardiac muscle. Am J Physiol. 1992;263: H622-33.

25. Headrick JP, McKirdy JC, Willis RJ. Functional and metabolic effects of extracellular magnesium in normoxic and ischemic myocardium. Am J Physiol. 1998; 275:H917-29. 